\title{
Antenatal care and women's decision making power as determinants of institutional delivery in rural area of Western Ethiopia
}

\author{
Tesfalidet Tekelab*, Birhanu Yadecha and Alemu Sufa Melka
}

\begin{abstract}
Background: Delivery by skilled birth attendance serves as an indicator of progress towards reducing maternal mortality. In Ethiopia, the proportions of births attended by skilled personnel were very low $15 \%$ and Oromia region $14.7 \%$. The current study identified factors associated with utilization of institutional delivery among married women in rural area of Western Ethiopia.

Methods: A community based cross-sectional study was employed from January 2 to January 31, 2015 among mothers who gave birth in the last 2 years in rural area of East Wollega Zone. A multi-stage sampling procedure was used to select 798 study participants. A pre-tested structured questionnaire was used to collect data and female high school graduates data collectors were involved in the data collection process. Bivariate and multivariable logistic regression model was fit and statistical significance was determined through a $95 \%$ confidence level.

Results: The study revealed that $39.7 \%$ of the mothers delivered in health facilities. Age 15-24 years (AOR 4.20, $95 \%$ Cl 2.07-8.55), 25-34 years (AOR 2.21, 95 \% Cl 1.32-3.69), women's educational level (AOR 2.00, 95 \% Cl 1.19-3.34), women's decision making power (AOR 2.11, $95 \% \mathrm{Cl}$ 1.54-2.89), utilization of antenatal care (ANC) during the index pregnancy (AOR 1.56, $95 \%$ Cl 1.08-2.23) and parity one (AOR 2.20, $95 \%$ Cl 1.10-4.38) showed significant positive association with utilization of institutional delivery.

Conclusion and recommendation: In this study proportion of institutional delivery were low (39.7\%). Age, women's literacy status, women's decision making power, ANC practice and numbers of live birth were found important predictors of institutional delivery. The findings of current study highlight the importance of boosting women involvement in formal education and decision making power. Moreover since ANC is big pillar for the remaining maternal health services effort should be there to increase ANC service utilization.
\end{abstract}

Keywords: Institutional delivery, Antenatal care, Decision making, Rural area

\section{Background}

Pregnancy and childbirth are generally times of joy for parents and families. The enabling environment for safe motherhood and childbirth depends on the care and attention provided to pregnant women and newborns by the expertise of skilled birth attendant and the availability of adequate health care facilities, equipment, and medicines and emergency care when needed [1].

*Correspondence: ttesfalove@gmail.com

College of Medical and Health Sciences, Wollega University, P.O.Box 395, Nekemte, Ethiopia
Globally, the maternal mortality ratio (MMR) has fallen by $45 \%$ between 1990 and 2013. There were an estimated 289,000 maternal deaths in 2013. Developing countries account for $99 \%$ of the global maternal deaths with sub Saharan Africa region alone accounting for $62 \%$. Ethiopia's MMR, 676 per 100,000 live births, is among the highest in the world. Together with only five other countries, namely: India, Nigeria, Pakistan, Afghanistan, and the Democratic Republic of Congo, Ethiopia contributes about $50 \%$ to the total global burden [2,3].

Maternal health care service utilization is important for the improvement of both maternal and child health 
and reduces maternal and child mortality and improves the reproductive health of the women. Improving maternal and child health requires increasing the percentage of women giving birth in health institutions with the assistance of trained staff, which is the central goal of the safe motherhood and child survival movements [4-7].

Proven and cost effective interventions can decrease neonatal deaths by three-quarters. Many of these interventions can be delivered through maternal health care service utilization including skilled birth attendant and health facility delivery which represent major chances to reach mothers and their newborn with lifesaving services that often bring better health outcome and developmental benefits. Improved care at birth or delivery is also the most effective strategy for reducing newborn mortality and stillbirths [8].

Delivery by skilled birth attendance serves as an indicator of progress towards reducing maternal mortality [9].

In developing regions overall, the proportion of deliveries attended by skilled birth attendant was $65 \%$ in 2010. The regions with the highest maternal mortality, sub-Saharan Africa and Southern Asia, are also those with the lowest coverage of births attended by skilled birth attendants less than half. There have been important improvements in maternal health and reduction in maternal deaths, but progress is still slow. Large disparities still exist in providing pregnant women with antenatal care (ANC) and skilled assistance during delivery. Poor women in remote areas are least likely to receive adequate care during childbirth. This is especially true for regions where the number of skilled birth attendant remains low and maternal mortality high particularly in sub-Saharan Africa [10, 11].

According to the 2014 Ethiopia Demographic and Health Survey (EDHS), the proportions of births attended by skilled personnel were very low $15 \%$ and Oromia region $14.7 \%$ [12]. In the study area information is lacking on the issue. Hence, this study was conducted to determine the prevalence of institutional delivery service utilization and associated factors in rural area of East Wollega Zone, Western Ethiopia.

\section{Methods}

\section{Study design, setting and participants}

A community-based cross-sectional study was carried out from January 2 to January 31, 2015 among mothers who gave birth in the last 2 years in rural area of East Wollega Zone, Oromia Region, West Ethiopia. East Wollega Zone is one of the zones of Oromia Regional state with a population of 1,230,402 among which 614,761 are males and 615,641 are females. Majority of the population live in rural areas $86 \%(1,061,120)$. Nekemte is the capital city of the zone which is located $331 \mathrm{~km}$ west of
Addis Ababa with a population of 76,817 (male 39,167 and female 37,650 ) [13]. The source population was all married women aged 15-49 years who gave at least one birth in the last 2 years preceding the survey. Study populations were randomly selected married women aged 15-49 years who gave at least one birth in the last 2 years preceding the survey. Women who were critically ill could not provide informed consent were excluded from the study.

\section{Sample size and sampling techniques}

The sample size was determined using a formula for estimation of single population proportion with the assumption of $95 \%$ confidence interval (CT), margin of error $5 \%$ and taking $61.6 \%$ institutional delivery prevalence of Holeta town, central Ethiopia [14] and a design effect of 2 . To avoid the effect of the design that decreases the representativeness of the study we used design effect. To compensate the non-response rate, $10 \%$ of the determined sample was added up on the calculated sample size and the final sample size was 801 .

A multi-stage sampling technique was employed for the selection of the sampling units. First, six districts were selected from 18 districts found in East Wollega Zone. Then 10 rural kebeles (lower administrative level) were randomly selected from a list of all kebeles found in the six districts. The calculated sample size was proportionally allocated to each kebeles based on the number of married women who gave birth in the past 2 years. Then picking a house randomly for the initial household from each kebele, the final households with married women were selected using systematic sampling from the existing sampling frame of households which were identified through census prior to data collection. Finally, eligible study subjects were interviewed from each selected households.

\section{Data collection procedures}

Pre-tested structured questionnaires were adapted from different literature [3, 12, 14-18] (Additional file 1). The questionnaires were prepared in English, translated into Afan Oromo (regional language), and then retranslated back to English by people who are proficient in both languages to maintain the consistency of the questionnaires. To administer the structured questionnaires, 12 female high school graduates were selected from the study area. Training was given for 3 days about the objective, relevance of the study, confidentiality of information, respondent's rights, informed consent and techniques of interview. Six supervisors who have second degree oversaw the data collection procedures. All field questionnaires were reviewed each night and issues that arose during data collection were addressed in morning sessions. 


\section{Data processing and analysis}

Data were cleaned and entered into a computer using Epi-Info window version 6.5 statistical programs. The data were then exported to SPSS windows version 20.0 for further analysis. The descriptive analyses such as proportions, percentages, frequency distribution and measures of central tendency were conducted.

Initially, bivariate analysis was performed between dependent variable and each of the independent variables, one at a time. Their odds ratios (OR) at $95 \% \mathrm{CI}$ and $\mathrm{p}$-values were obtained. The findings at this stage helped us to identify important associations. Then all variables found to be significant at bivariate level (at $p<0.05$ ) were entered into multivariate analysis using the logistic regression model to test the significance of the association.

\section{Definition of terms}

Skill birth attendant means having an accredited health professional, including a midwife, doctor, or nurse, who has been trained in the skills needed to needed to manage a normal or uncomplicated pregnancy and childbirth and to support the woman in the immediate postpartum period.

Institutional delivery means women who gave birth at health facility (Hospital or health center).

Home deliveries means delivery attended by non-skilled birth attendant in this study.

\section{Ethical considerations}

Ethical clearance and permission was obtained from Wollega University Institutional Review Board. Permission was secured from all kebeles through a formal letter. Written informed consent was obtained from each respondent before their interview. The written informed consent was also includes study participants less than 18 years since they were married and minor mature and the consent procedure was approved by ethics committee of Wollega University. Confidentiality of individual client information was ensured by using unique identifiers for the study participants and also limiting access to respondents' information to the principal investigator and research assistants by storing the completed questionnaires and all documents with participant information in a lockable cabinet.

\section{Results}

\section{Socio-demographic characteristics}

A total of 798 mothers who gave birth in the last 2 years were responded to the questionnaire, making a response rate of $99.6 \%$. Five hundred eleven (64.0\%) were in the age group of 25-34 years with mean age of 29.5 years $(\mathrm{SD} \pm 5.3$ years). Majority $(94.2 \%)$ were from Oromo ethnic group. More than half of the respondents
(58.0 \%) were protestant in religion. Nearly half (47.6\%) respondents can't read and write, whereas $(29.1 \%)$ of the respondents' husbands had attended grade 1-4. Six hundred thirty five $(79.6 \%)$ of the respondent and their husbands $(81.1 \%)$ were housewives and farmer, respectively. Their mean monthly income was ETB 841.01. Out of the total mother, $45.0 \%$ owned radio/TV (Table 1 ).

\section{Obstetric characteristics}

Five hundred seven (63.5\%) of the study subjects had two to four children. Majority (92.1\%) of the respondents had no history of abortion. Four hundred ninety four (61.9\%) of the respondents had visited health facilities for ANC purposes during their last pregnancy. Among the mothers who attended ANC, 294 (59.5\%) of them visited health facilities two to three times (Table 2).

\section{Awareness and place of delivery}

From the total study participants $81.0 \%$ of them heard about institutional delivery and $32.7 \%$ of them heard about institutional delivery from health workers. More than three-fourth $(76.3 \%)$ of the respondent knew a health problem occur during child birth. Two hundred forty nine $(40.9 \%)$ of the respondent mentioned maternal death as a health problem occurring during child birth. Three hundred seventeen $(39.7 \%)$ of the respondent gave birth at health facilities and more than half $(60.3 \%)$ of respondent gave birth at home (Table 3 ).

\section{Reason for home delivery}

Among 481 mother who delivered at home 386 (80.2\%) reported that they prefer to deliver at home because the labour was going well (Fig. 1).

Factors associated with utilization of institutional delivery In multivariate analysis revealed that mothers with age group of 15-24 years were four times more likely to give birth in the health institution than mothers with age group 35-44 years (AOR 4.20, 95 \% CI 2.07-8.55), while mothers aged 25-34 years were two times more likely to have birth at health facility than mothers with age group 35-44 years (AOR 2.21, 95 \% CI 1.32-3.69). Those respondents who had secondary school education and above were two times more likely to give birth in health institution than those with primary education and below (AOR 2.00, 95 \% CI 1.19-3.34). Those women who decide place of birth by themselves were two times more likely to use institutional delivery than mother whom decision where to give birth made by husband and family members (AOR 2.11, 95 \% CI 1.54-2.89). Mother who attended ANC service for the index pregnancy was nearly two times more likely to use institutional delivery than their counterpart (AOR 1.56, 95 \% CI 1.08-2.23). 
Table 1 Socio demographic characteristics of respondents in rural area of East Wollega Zone, Western Ethiopia, January, 2015

\begin{tabular}{|c|c|}
\hline Variables (798) & Number (\%) \\
\hline \multicolumn{2}{|l|}{ Age category } \\
\hline $15-24$ & $116(14.5)$ \\
\hline $25-34$ & $511(64.0)$ \\
\hline $35-44$ & $171(21.4)$ \\
\hline \multicolumn{2}{|l|}{ Ethnicity } \\
\hline Oromo & $752(94.2)$ \\
\hline Amhara & $40(5.0)$ \\
\hline Tigre & $6(0.8)$ \\
\hline \multicolumn{2}{|l|}{ Religion } \\
\hline Protestant & $463(58.0)$ \\
\hline Ethiopian orthodox & $312(39.1)$ \\
\hline Catholic & $3(0.4)$ \\
\hline Muslim & $19(2.4)$ \\
\hline Others $^{\mathrm{a}}$ & $1(0.1)$ \\
\hline \multicolumn{2}{|c|}{ Educational status of the respondent } \\
\hline Can't read and write & $380(47.6)$ \\
\hline Can read and write & $57(7.1)$ \\
\hline Grade $1-4$ & $154(19.3)$ \\
\hline Grade 5-8 & $78(9.8)$ \\
\hline Secondary & $117(14.7)$ \\
\hline College and above & $12(1.5)$ \\
\hline \multicolumn{2}{|c|}{ Educational status of the husband } \\
\hline Can't read and write & $88(11.0)$ \\
\hline Can read and write & $132(16.5)$ \\
\hline Grade 1-4 & $232(29.1)$ \\
\hline Grade 5-8 & $196(24.6)$ \\
\hline Secondary & $114(14.3)$ \\
\hline College and above & $36(4.5)$ \\
\hline \multicolumn{2}{|c|}{ Occupational status of the respondents } \\
\hline Housewife & $635(79.6)$ \\
\hline Governmental employee & $37(4.6)$ \\
\hline Daily laborer & $77(9.6)$ \\
\hline Merchant & $40(5.0)$ \\
\hline Student & $9(1.1)$ \\
\hline \multicolumn{2}{|c|}{ Occupational status of the husband } \\
\hline Farmer & $647(81.1)$ \\
\hline Governmental employee & $71(8.9)$ \\
\hline Daily laborer & $29(3.6)$ \\
\hline Merchant & $35(4.4)$ \\
\hline Student & $16(2.0)$ \\
\hline \multicolumn{2}{|l|}{ Income (ETB) } \\
\hline$<490$ & $200(25.1)$ \\
\hline $491-700$ & $216(27.1)$ \\
\hline $701-1000$ & $230(28.8)$ \\
\hline$>1000$ & $152(19.0)$ \\
\hline Mean & $841.01 \mathrm{ETB}$ \\
\hline
\end{tabular}

Table 1 continued

\begin{tabular}{ll}
\hline Variables (798) & Number (\%) \\
\hline Have radio/TV & \\
Yes & $359(45.0)$ \\
No & $439(55.0)$ \\
\hline
\end{tabular}

adventist ETB Ethiopian Birr 1\$=20.2 ETB

Table 2 Obstetrics history of respondents in rural area of East Wollega Zone, Western Ethiopia, January, 2015

\begin{tabular}{lc}
\hline Variables & Number (\%) \\
\hline Parity (798) & \\
1 & $101(12.7)$ \\
$2-4$ & $507(63.5)$ \\
$\geq 5$ & $190(23.8)$ \\
Abortion in life time & \\
Yes & $63(7.9)$ \\
No & $735(92.1)$ \\
ANC visit during last pregnancy & \\
Yes & $494(61.9)$ \\
No & $304(38.1)$ \\
Number ANC visit during last pregnancy & \\
Only one & $129(26.1)$ \\
Two to three & $294(59.5)$ \\
Four and above & $71(14.4)$ \\
\hline
\end{tabular}

Table 3 Awareness and place of delivery of the respondents in rural area of East Wollega Zone, Western Ethiopia, January, 2015

\begin{tabular}{lc}
\hline Variables & Number (\%) \\
\hline Ever heard of institutional delivery (798) & \\
Yes & $646(81.0)$ \\
No & $152(19.0)$ \\
Source of information on institutional delivery (646) & \\
Health worker & $211(32.7)$ \\
Radio/TV & $72(11.1)$ \\
Family/relatives & $25(3.9)$ \\
Friends & $23(3.6)$ \\
Others & $5(0.8)$ \\
Knew a health problem occur during child birth (798) & \\
Yes & $609(76.3)$ \\
No & $189(23.7)$ \\
Mention the problem (609) & \\
Severe bleeding & $429(70.4)$ \\
Obstructed labour & $98(16.1)$ \\
Fetal death & $238(39.1)$ \\
Maternal death & $249(40.9)$ \\
Others & $25(4.1)$ \\
Place of last 12 month delivery (798) & \\
Home & $481(60.3)$ \\
Health facility & $317(39.7)$ \\
\hline
\end{tabular}




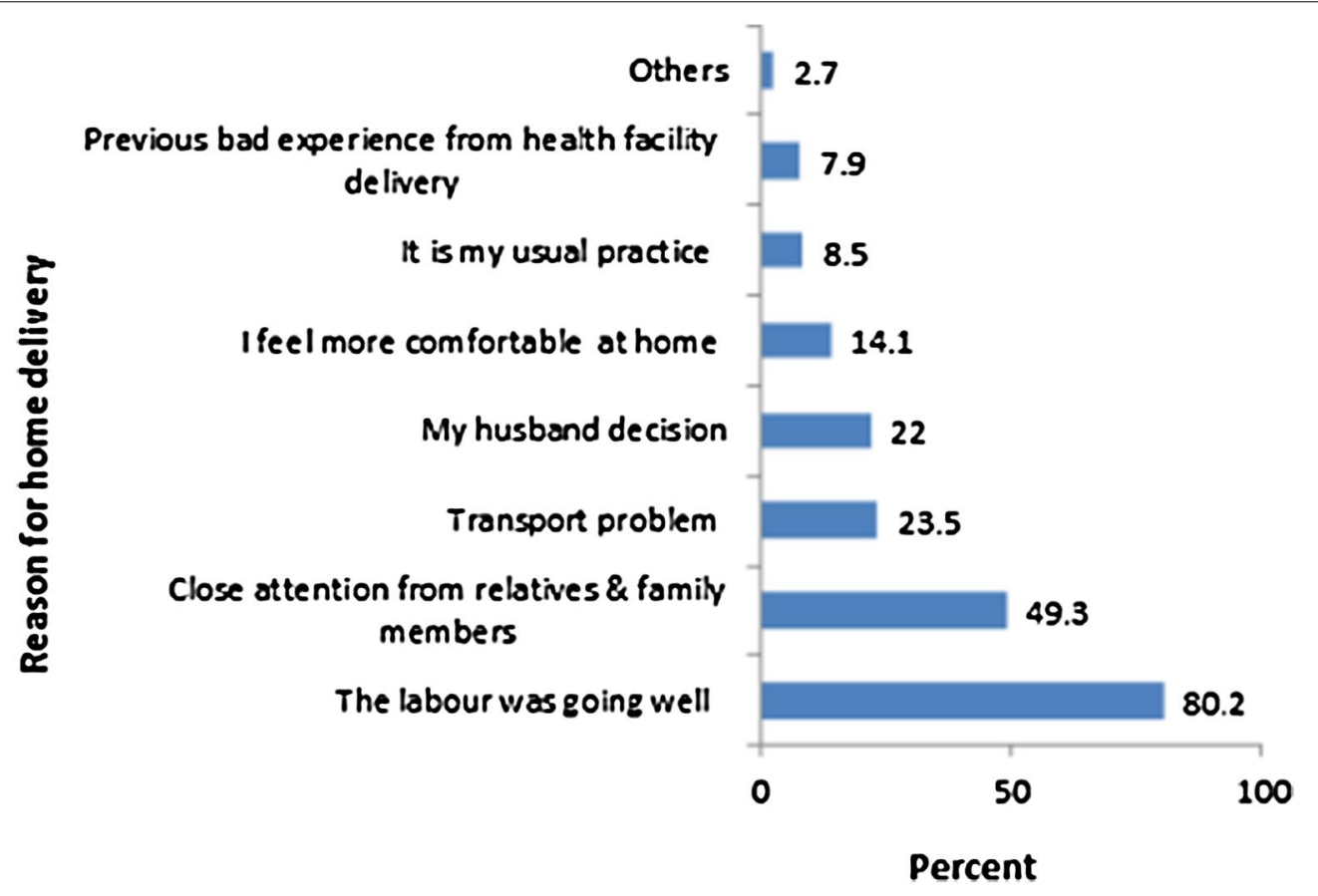

Fig. 1 Bar graphs showing reasons for home delivery among mothers in rural area of East Wollega Zone, Western Ethiopia, January, 2015

Mothers with parity of one had two times the likelihood of utilizing institutional delivery service than mothers with two parity and above (AOR 2.20, $95 \%$ CI 1.10-4.38) (Table 4).

\section{Discussion}

This community-based study identified the institutional delivery service utilization and associated factors among mothers who gave birth in the last 2 years prior to the study in rural area of East Wollega Zone. The finding of this study showed that $39.7 \%$ of the births were attended in the health institution. The finding was much higher than previous studies in Ethiopia [12, 15, 16]. The difference might be due to the time gap of the studies and there could be improvement in utilizing maternal health care service through health extension workers and governmental commitment to decrease maternal mortality by increasing number of birth attended by skilled birth attendants and health facilities. The finding was lower than study done in Holeta town, central Ethiopia which was $61.6 \%$ [14]. This might be due to the fact that Holeta town is near to the capital city of Ethiopia and could have better opportunities for information and better access to health institutions than rural areas.

The main reasons given by mothers for home delivery was $80.2 \%$ reported that they prefer to deliver at home because the labour was going well, 237 (49.3\%) where close attention from relatives and family members. The finding was similar to previous studies done in Ethiopia $[14,17]$. The study highlight the importance of emphasizing on improving women's awareness on the risk associated with home deliveries.

Institutional deliveries were more common among births to mothers below age 35 years [12]. In this study, mothers whose age category was $15-24$ and 25-34 years were more likely to use institutional delivery service than mothers with age group 35-44 years. It is consistent with previous studies $[15,19]$. The possible explanation might be older mother may believe that there is less risk to home delivery due to previous knowledge of their pregnancy and delivery.

According to EDHS, highly educated mothers were most likely to have their births assisted by a skilled provider $74 \%$ [3]. Previous studies conducted in developing countries have been found that high education level was associated with a high proportion of facility deliveries. In this study, mothers who attended secondary education and above were two times more likely to give birth in health institution than those mothers who had primary education and below [18, 20-25]. The findings of current study calls for working on improving women's participation on formal education.

In previous studies mothers autonomy is associated with maternal health care service utilization including place of delivery and delivery assisted by skilled birth attendant $[14,26-31]$. In the current study mother for 
Table 4 A multivariate Logistic regression on determinant of institutional delivery in rural area of East Wollega Zone, Oromia region, Western Ethiopia, January, 2015

\begin{tabular}{|c|c|c|c|c|}
\hline \multirow[t]{2}{*}{ Characteristics } & \multicolumn{2}{|c|}{ Utilization of institutional delivery } & \multirow{2}{*}{$\begin{array}{l}\text { Crude OR } \\
\text { OR (CI) }\end{array}$} & \multirow{2}{*}{$\begin{array}{l}\text { Adjusted OR } \\
\text { OR (CI) }\end{array}$} \\
\hline & Yes (\%) & No (\%) & & \\
\hline \multicolumn{5}{|l|}{ Age category in years } \\
\hline $15-24$ & $80(69.0 \%)$ & $36(31.0 \%)$ & $10.04(5.77-17.45)$ & $4.20(2.07-8.55)^{*}$ \\
\hline $25-34$ & $206(40.3 \%)$ & $305(59.7 \%)$ & $3.05(1.99-4.68)$ & $2.21(1.32-3.69)^{*}$ \\
\hline $35-44$ & $31(18.1 \%)$ & $140(81.9 \%)$ & 1 & 1 \\
\hline \multicolumn{5}{|l|}{ Education of respondents } \\
\hline Below and primary & $234(35.0 \%)$ & $435(65.0 \%)$ & 1 & 1 \\
\hline Secondary and above & $83(64.3 \%)$ & $46(35.7 \%)$ & $3.35(2.26-4.79)$ & $2.00(1.19-3.34)^{*}$ \\
\hline \multicolumn{5}{|l|}{ Education of husband } \\
\hline Below and primary & $243(37.5 \%)$ & $405(62.5 \%)$ & 1 & 1 \\
\hline Secondary and above & $74(49.3 \%)$ & $76(50.7 \%)$ & $1.62(1.14-2.32)$ & $0.92(0.53-1.97)$ \\
\hline \multicolumn{5}{|c|}{ Occupation of respondents } \\
\hline House wife & $233(36.7 \%)$ & $402(63.3 \%)$ & $1.99(1.40-2.81)$ & 1 \\
\hline Others & $84(51.5 \%)$ & $79(48.5 \%)$ & 1 & $1.42(0.95-2.14)^{*}$ \\
\hline \multicolumn{5}{|l|}{ Husband occupation } \\
\hline Farmer & $244(37.7 \%)$ & $403(62.3 \%)$ & $1.55(1.08-2.21)$ & 1 \\
\hline Others & $73(48.3 \%)$ & $78(51.7 \%)$ & 1 & $0.85(0.49-1.45)$ \\
\hline \multicolumn{5}{|c|}{ Decision where to give birth } \\
\hline Self & $187(50.1 \%)$ & $186(49.9 \%)$ & $2.28(1.71-3.05)$ & $2.11(1.54-2.89)^{*}$ \\
\hline Others & $130(30.6 \%)$ & $295(69.4 \%)$ & 1 & 1 \\
\hline \multicolumn{5}{|c|}{ Use of ANC during the index pregnancy } \\
\hline Yes & $240(48.6 \%)$ & $254(51.4 \%)$ & 1 & $1.56(1.08-2.23)^{*}$ \\
\hline No & $77(25.3 \%)$ & $227(774.7 \%)$ & $2.79(2.04-3.81)$ & 1 \\
\hline \multicolumn{5}{|l|}{ Parity } \\
\hline 1 & $71(70.3 \%)$ & $30(29.7 \%)$ & $7.63(4.43-13.12)$ & $2.20(1.10-4.38)^{*}$ \\
\hline $2-4$ & $201(39.6 \%)$ & $306(60.4 \%)$ & $2.12(1.45-3.10)$ & $1.24(0.80-1.92)$ \\
\hline$\geq 5$ & $45(23.7 \%)$ & $145(76.3 \%)$ & 1 & 1 \\
\hline \multicolumn{5}{|l|}{ Possessing radio/and TV } \\
\hline Yes & 157 (43.7 \%) & $202(56.3 \%)$ & $1.36(1.02-1.80)$ & $1.02(0.72-1.43)$ \\
\hline No & $160(36.4 \%)$ & $279(63.6 \%)$ & 1 & 1 \\
\hline
\end{tabular}

* Statistically significant ( $\mathrm{p}$-value <0.05) 1 Reference category

whom the decision on place of delivery made by themselves were two times more likely to give birth in health institution than mother whom decision where to give birth made by others.

Mother who attended ANC service for the index pregnancy was nearly two times more likely to use institutional delivery than their counterpart. This study is similar with studies done elsewhere [17, 32-36]. This could be due to the information mother received during the ANC follow up about the importance of delivering at health institution assisted with skilled birth attendant from the health care provider which could have influenced their decision to deliver with assistant of skilled birth attendant in the health institution.
As parity level increased, women were less likely to give birth in health institution compared with low parity women (women with 1-2 live births) [14, 23, 24, 37, 38]. In this study mothers with parity of one had two times the likelihood of using health facilities than mothers with two parity and above. The possible reason could be mothers who have one child tend to be more concerned about complications than those who have had two or more previous deliveries; hence, they tend to choose skilled birth attendant.

The limitation of this study was the cross-sectional nature of the data that could obscure the causal effect relationships of different factors. In addition it lacks qualitative data. 


\section{Conclusion and recommendation}

In this study proportion of institutional delivery were low $(39.7 \%)$. Age, women's literacy status, women's decision making power, ANC practice and numbers of live birth were found important predictors of institutional delivery. The findings of current study highlight the importance of scaling up of women's formal education and decision making power. Moreover since ANC is big pillar for the remaining maternal health care services effort should be there to increase ANC utilization.

\section{Additional file}

Additional file 1. Questionnarie.

\section{Authors' contributions}

TT wrote the proposal and TT, BY, AS participated in developing the tools and data collection process. TT performed analysis and interpretation of the data and drafted the paper and prepared the manuscript. All authors read and approved the final manuscript.

\section{Authors' information}

TT is Lecturer of Reproductive and Maternal Health, Department of Nursing and Midwifery, College of Medical and Health Sciences, Wollega University, Ethiopia. BY is lecturer of adult health Nursing, Department of Nursing and Midwifery, College of Medical and Health Sciences, Wollega University, Ethiopia.AS is Lecturer of Reproductive Health, Department of Public Health, College of Medical and Health Sciences, Wollega University, Ethiopia.

\section{Acknowledgements}

We would like to acknowledge Wollega University for funding this research project. Our sincere gratitude also goes to all supervisors, data collectors and study participants for their cooperation and support during the study period.

\section{Competing interests}

The authors declare that they have no competing interests.

Received: 29 June 2015 Accepted: 17 November 2015

Published online: 11 December 2015

\section{References}

1. UNICEF. The state of the world's children; Maternal and Newborn Health. 2009.

2. WHO, UNICEF, UNFPA and the World Bank. Trends in maternal mortality: 1990 to 2013. Estimates by WHO, UNICEF, UNFPA, The World Bank and the United Nations Population Division. 2014.

3. Central Statistical Agency, Ethiopia and ORC Macro: Ethiopia Demographic and Health Survey (EDHS) 2011. Addis Ababa, Ethiopia and Calverton, Maryland, USA. Central Statistical Agency and ORC Macro. 2012:93-99.

4. Stephenson R, Baschieri A, Clements S, Hennink M, Madise N. Contextual influences on the use of health facilities for childbirth in Africa. Am J Public Health. 2006;96(1):84-93.

5. Kesterton J, Cleland J, Sloggett A, Ronsmans C. Institutional delivery in rural India: the relative importance of accessibility and economic status. BMC Pregnancy Childbirth. 2010;10(30):1.

6. Gokhale MK, Rao SS, Garole VR. Infant mortality in India: use of maternal and child health services in relation to literacy status.J Health Popul Nutr. 2002;20(2):138-47.

7. Suwal J. Maternal mortality in Nepal unraveling the complexity. Can Stud Popul. 2008;35(1):1-26.

8. Lawn J, Blencowe H, Pattinson R, Cousens S, Kumar R, Ibiebele I, et al. Stillbirths: Where? When? Why? How to make the data count. Lancet. 2011;377(9775):1448-63.
9. Baral YR, Lyons K, Skinner J, van Teijlingen ER. Determinants of skilled birth attendants for delivery in Nepal. Kathmandu Univ Med J. 2010;8(31):325-32.

10. UN. Millennium development goals report. 2012.

11. UN. Millennium development goals. 2010.

12. Central Statistical Agency Ethiopia: Ethiopia Mini Demographic and Health Survey 2014. Addis Ababa, Ethiopia. 2014.

13. Federal Democratic Republic of Ethiopia: Population Census Commission. Summary and statistical report of the 2007 population and Housing census. Population size by age and sex Addis Ababa. 2008.

14. Birmeta K, Dibaba Y, Woldeyohannes D. Determinants of maternal health care utilization in Holeta town, central Ethiopia. BMC Health Serv Res. 2013;13:256.

15. Teferra A, Alemu F, Woldeyohannes S. Institutional delivery service utilization and associated factors among mothers who gave birth in the last 12 months in Sekela District, north west of Ethiopia: a community-based cross sectional study. BMC Pregnancy Childbirth. 2012;12:74.

16. Fikre A, Demissie M. Prevalence of institutional delivery and associated factors in Dodota Woreda (district), Oromia regional state, Ethiopia. Reprod Health. 2012;9(33):4755-9.

17. Tsegay Y, Gebrehiwot T, Goicolea I, Edin K, Lemma H, Sebastian MS. Determinants of antenatal and delivery care utilization in Tigray region, Ethiopia: a cross-sectional study. Int J Equity Health. 2013;12(30):1475-9276.

18. Tarekegn S, Lieberman L, Giedraitis V. Determinants of maternal health service utilization in Ethiopia: analysis of the 2011 Ethiopian demographic and health survey. BMC Pregnancy Childbirth. 2014;14:161.

19. Mesfin N, Damen H, Getnet M. Assessment of safe delivery service utilization among women of child bearing age in North Gondar Zone. Ethiop J Health Dev. 2004;18(3):146-50.

20. Hounton S, Chapman G, Menten J, De Brouwere V, Ensor T, Sombié I, Meda N, Ronsmans C. Accessibility and utilization of delivery care within a skilled care initiative in rural Burkina Faso. Trop Med Int Health. 2008;13(Suppl 1):44-52.

21. Hazemba AN, Siziya S. Choice of place for childbirth: prevalence and correlates of utilization of health facilities in Chongwe district Zambia. Med J Zambia. 2008;35(2):53-7.

22. Mrisho M, Schellenberg J, Mushi A, Obrist B, Mshinda H, Tanner M, Schellenberg D. Factors affecting home delivery in rural Tanzania. Trop Med Int Health. 2007;4(2):862-72.

23. van Eijk AM, Bles HM, Odhiambo F, Ayisi JG, Blokland IE, Rosen DH, Adazu K, Slutsker L, Lindblade KA. Use of antenatal services and delivery care among women in rural western Kenya: a community based survey. Reprod Health. 2006;3:2

24. Melaku Y, Weldearegawi B, Tesfay F, Abera S, Abraham L, Aregay A, et al. Poor linkages in maternal health care services evidence on antenatal care and institutional delivery from a community-based longitudinal study in Tigray region Ethiopia. BMC Pregnancy Childbirth. 2014;14:418.

25. Abebe F, Berhane Y, Girma B. Factors associated with home delivery in Bahirdar, Ethiopia: a case control study. BMC Res Notes. 2012;5:653.

26. Asweto O, Ouma O, Aluoch R, Obonyo O. Women empowerment and skilled attendance/facility delivery in a rural community of western Kenya. IOSR-JNHS. 2014;3(2):48-53

27. Speizer I, Story W, Singh K. Factors associated with institutional delivery in Ghana: the role of decision-making autonomy and community norms. BMC Pregnancy Childbirth. 2014;14:398.

28. Gabrysch S, Campbell OM. Still too far to walk: literature review of the determinants of delivery service use. BMC Pregnancy Childbirth. 2009:9:34.

29. Agha S, Carton T. Determinants of institutional delivery in rural Jhang, Pakistan. Int J Equity Health. 2011;10:31.

30. Story WT, Burgard SA. Couples' reports of household decision-making and the utilization of maternal health services in Bangladesh. Soc Sci Med. 2012;75(12):2403-11.

31. Abera M, G/mariam A, Belachew T. Predictors of safe delivery service utilization in Arsi Zone, South-East Ethiopia. Ethiop J Health Sci. 2011;21(Special Issue 1):95-106.

32. Hagos S, Shaweno D, Assegid M, Mekonnen A, Afework M, Ahmed S. Utilization of institutional delivery service at Wukro and Butajera districts in the Northern and South Central Ethiopia. BMC Pregnancy Childbirth. 2014;14:178. 
33. Mpembeni RN, Killewo JZ, Leshabari MT, Massawe SN, Jahn A, Mushi D, Mwakipa $\mathrm{H}$. Use pattern of maternal health services and determinants of skilled care during delivery in Southern Tanzania: implications for achievement of MDG-5 targets. BMC Pregnancy Childbirth. 2007;6:7-29.

34. Gage AJ. Barriers to the utilization of maternal health care in rural Mali. Soc Sci Med. 2007;65(8):1666-82

35. Odo D, Shifti D. Institutional delivery service utilization and associated factors among child bearing age women in goba woreda, Ethiopia. J Gynecol Obstet. 2014;2(4):63-70
36. Bayu H, Adefris M, Amano A, Abuhay M. Pregnant women's preference and factors associated with institutional delivery service utilization in Debra Markos Town, North West Ethiopia: a community based follow up study. BMC Pregnancy Childbirth. 2015;15:15

37. Dorothy $\mathrm{O}$, Clifford O. Determinants of maternal health care utilization in Nigeria: a multilevel approach. Pan Afr Med J. 2014;17(1):2.

38. Mekonnen Y, Mekonnen A. Factors influencing the use of maternal health care services in Ethiopia. J Health Popul Nutr. 2003;21(4):374-82.
Submit your next manuscript to BioMed Central and we will help you at every step:

- We accept pre-submission inquiries

- Our selector tool helps you to find the most relevant journal

- We provide round the clock customer support

- Convenient online submission

- Thorough peer review

- Inclusion in PubMed and all major indexing services

- Maximum visibility for your research

Submit your manuscript at www.biomedcentral.com/submit
(O) BioMed Central 